\title{
The impact of mitochondrial function/dysfunction on IVF and new treatment possibilities for infertility
}

Heide Schatten ${ }^{1^{*}}$, Qing-Yuan Sun ${ }^{2}$ and Randall Prather ${ }^{3,4}$

\begin{abstract}
Mitochondria play vital roles in oocyte functions and they are critical indicators of oocyte quality which is important for fertilization and development into viable offspring. Quality-compromised oocytes are correlated with infertility, developmental disorders, reduced blastocyst cell number and embryo loss in which mitochondrial dysfunctions play a significant role. Increasingly, women affected by metabolic disorders such as diabetes or obesity and oocyte aging are seeking treatment in IVF clinics to overcome the effects of adverse metabolic conditions on mitochondrial functions and new treatments have become available to restore oocyte quality. The past decade has seen enormous advances in potential therapies to restore oocyte quality and includes dietary components and transfer of mitochondria from cells with mitochondrial integrity into mitochondria-impaired oocytes. New technologies have opened up new possibilities for therapeutic advances which will increase the success rates for IVF of oocytes from women with compromised oocyte quality.
\end{abstract}

Keywords: Mitochondria, Oocytes, Embryos, Embryo development, Metabolism, In vitro fertilization, Mitochondrial supplementation, Infertility treatment

\section{Background}

Mitochondria play vital roles in oocyte functions and they are critical indicators of oocyte quality. Among the major mitochondrial functions is the production of adenosine triphosphate (ATP) to provide energy, but unlike in somatic cells, ATP in most mammalian oocytes is mainly generated through the glycolytic and Pentose Phosphate Pathway (PPP) rather than the oxidative phosphorylation (OXPHOS) pathway $[1,2]$ used by most differentiated somatic cells. Correlated with these metabolic differences are significant structural differences; since the embryo primarily uses glycolysis and PPP, the mitochondria are round and contain few cristae, while mitochondria using the OXPHOS pathway display elongated shapes and contain an elaborate system of cristae that distinguishes the inner mitochondrial membrane. Changes in mitochondrial structure from the round (immature) phenotype to the elongated (mature, differentiated) phenotype takes place during embryogenesis

\footnotetext{
* Correspondence: SchattenH@missouri.edu

'Department of Veterinary Pathobiology, University of Missouri, Columbia, MO, USA

Full list of author information is available at the end of the article
}

when cells differentiate and mitochondrial metabolism changes from primarily glycolysis to OXPHOS.

Compared to our knowledge of mitochondria in somatic cells, relatively little is known about mitochondria in oocytes and in the preimplantation embryo but it is well known that mitochondrial dysfunction in the oocyte and embryo play significant roles in infertility and in developmental abnormalities [3-7].

Fertility disorders have become a growing problem worldwide $[8,9]$, and mitochondrial dysfunction associated with infertility have clearly been shown in women affected by diseases or metabolic disorders such as diabetes and obesity [3,10-12] as well as changes in metabolism resulting from oocyte aging [8,11-17]. Other mitochondrial dysfunctions are still unexplained but have resulted in an increased number of women requiring in vitro fertilization (IVF) or other assisted reproductive technologies (ARTs). Currently, one percent of all babies in the Western world are already being produced through ART and the numbers are increasing reviewed in $[8,9,18,19]$.

The effects of mitochondrial dysfunctions as well as sub-optimal mitochondrial functions are correlated with 
meiotic spindle abnormalities. As will be addressed in more detail below, mitochondrial functions are important for the formation of meiotic spindles and for maintenance of the MII spindle before fertilization. Insufficient ATP generation will result in aneuploidy, a condition in which chromosomal segregation errors are frequently encountered. In human, oocyte chromosomal segregation is error-prone and these errors have been estimated to be about $15-20 \%$ [20] and 5\% of all pregnancies are aneuploid [21]; reviewed in [19]. The frequency of aneuploidy increases significantly in oocytes from obese or diabetic females [3,10-12] and in aging oocytes [8,11,12,14,15], as will be discussed in section 2 . While cytoplasmic transfer from healthy donor oocytes with fully functional mitochondria has been successfully applied to overcome mitochondrial dysfunctions in quality-compromised oocytes $[6,8,11,12,14,15,22,23]$ the procedures raised concerns including ethical concerns, but new studies clarified the potential risks; such as introducing heteroplasmy or mitochondrial genetic disease [24]; reviewed in 6. These techniques have resulted in new possibilities to overcome mitochondrial dysfunction in quality-compromised oocytes [25-31]. The present review will address: 1) Mitochondrial structure, dynamics, characteristics, and their functions in oocyte maturation, fertilization and embryo development; 2) Mitochondrial dysfunction in qualitycompromised oocytes; and 3) Possibilities to overcome mitochondrial dysfunctions in oocytes to improve IVF success rates.

\section{Section 1: mitochondrial structure, dynamics, characteristics and their functions in oocyte maturation, fertilization, and embryo development}

Based on the significant need to increase success rates in IVF clinics new strategies are in demand to overcome mitochondrial dysfunctions, but before therapeutic interventions can be applied the metabolic activities and dynamics of mitochondria in unaffected oocytes and embryos need to be understood more fully. Many aspects of mitochondrial function and dysfunction are still unexplored in oocytes and preimplantation embryos and many questions remain to be answered. This section will address our current understanding of mitochondrial dynamics and highlight the aspects that still need clarification.

Mitochondria are multifunctional organelles with critical functions in cellular energy production, calcium homeostasis [32], cell signaling, apoptosis [33] and several other cellular processes [34]; reviewed in [35,36]. Mitochondria dynamics and motility are correlated with mitochondrial functions and mitochondria have an enormous ability to modulate their functions, dynamic behavior, and metabolic activities, depending on different environmental conditions. Most studies on mitochondrial metabolism, dynamics, biochemistry, molecular composition and related functions have been performed in somatic cells in which mitochondrial dysfunctions have been correlated with specific structural and molecular abnormalities associated with diseases such as neurological disorders, heart disease, diabetes, and cancer; reviewed in [35,36].

Mitochondria are semiautonomous organelles that contain their own genome of ca. $16.6 \mathrm{~kb}$ circular mitochondrial DNA (mtDNA), encoding for 13 essential protein subunits of complexes I, III, IV, and V of the respiratory chain of the mitochondrial OXPHOS complexes as well as 22 tRNAs used in mitochondrial protein synthesis and 2 rRNAs (12 s and $16 \mathrm{~s}$ ) that are necessary for the translation of mitochondrial subunits [37]. A functionally close and important relationship exists between the nuclear genome and the mitochondrial genome with about 1,500 mitochondrial-related genes that are critical for mitochondrial function residing in the nuclear genome [38-40]. Transcripts for most of the mitochondrial polypeptides are translated in the cytoplasm and imported into the mitochondria. Examples include the mitochondrial transcription factor A (TFAM) [41,42] that is required for mtDNA replication; and transcription of TFAM is correlated with transcription of catalytic DNA polymerase gamma (POLG) and accessory POLYG2 subunits [43].

In addition to mitochondrial activity being dependent on overall mitochondrial dynamics and motility, mitochondrial activities depend on several specific mitochondrial features and characteristics that are important for cell cycle-specific functions and include the mitochondrial transition pore $(\mathrm{mPT})$, membrane potential, localization and distribution patterns, and adequate amounts of mtDNA. Dysfunctions involve increases in reactive oxygen species (ROS) and calcium overload; reviewed in $[3,8,11,12,14-16]$.

The mitochondrial permeability transition pore (mPT) is a nonselective and high-conductance channel composed of ANT, the voltage-dependent anion channel (VDAC), and cyclophilin-D [44]. The mPTP is localized to the inner membrane and an increase of mitochondrial inner membrane permeability to ions and solutes with molecular masses up to about 1,500 Da leads to matrix swelling [45]. Changes in the mPTP are important for mitochondrial maturation, as shown in differentiating cardiomyocytes [46].

Mitochondrial membrane potential $(\Psi \mathrm{m})$ results from mitochondrial activity, and is highly important for oocyte quality; conversely lowly-polarized mitochondria in oocytes result in abnormal embryos [47]. Several probes are available to determine $\Psi \mathrm{m}$ and includes the mitochondrial membrane potential indicator 5,5',6,6'-tetrachloro-1,1'3,3'tetraethylbenzamidazol-carboncyanine (JC-1) [11,48]. JC-1 is a cationic dye whose mitochondrial uptake is directly related to the level of $\Psi \mathrm{m}$. A greater concentration of JC-1 aggregate is correlated with greater mitochondrial uptake resulting in a red fluorescent emission signal; while green 
fluorescence indicates the presence of JC-1 as monomer. A higher red:green ratio indicates a more polarized, or more negative and hyperpolarized mitochondrial inner membrane. JC-1 has been used to measure mitochondrial maturation and distinguish immature from mature mitochondria.

In somatic cells, mitochondria form a highly complex dynamic network and they undergo fusion and fission to accommodate the functional requirements of specific cell types. In most cell types mitochondria are translocated along microtubules to their functional destinations [49] using the microtubule motor proteins dynein and kinesin for effective intracellular translocations [50]. Mitochondrial locations can change depending on their cell cycle-specific function. In some cases activity is required at specific localized areas in a cell. For example, mitochondria become localized to the nuclear periphery prior to nuclear envelope breakdown. This localization of mitochondria indicates positive developmental potential while mitochondria dispersed in the cytoplasm at the predicted time for nuclear envelope breakdown is indicative of cells or embryos with less developmental potential $[49,51]$.

As mentioned in the introduction, in contrast to differentiated cells, early embryo cells, like pluripotent stem cells, contain mitochondria that display a round morphology and only few cristae (Figure 1), generally referred to as functionally immature mitochondria and are characteristic of undifferentiated cells. While we do not yet have complete and detailed knowledge about specific mitochondrial functions in embryonic cells we know that mitochondria are important for oocyte maturation, fertilization, and preimplantation development and may contribute ATP for energy-consuming events such as nuclear envelope breakdown, and microtubule assembly and disassembly for meiotic and mitotic spindle assembly.

Oocyte maturation: Mitochondria are critically important for oocyte maturation and they are reliable indicators for oocyte quality achieved during the maturation process. Mammalian oocytes are arrested at the germinal vesicle $(\mathrm{GV})$ stage in the ovary of the newborn which is the diakinesis stage of prophase I. These arrested oocytes remain at the GV stage until puberty, when folliclestimulating hormone (FSH) induces development of small antral follicles into the pre-ovulatory stage. Oocyte maturation in the ovary continues with the resumption of meiosis from prophase I (germinal vesicle stage; GV) and the extrusion of the first polar body (PBI) followed by initiation of meiosis II and oocyte arrest at the metaphase II stage of second meiosis. The number of mitochondria varies in different species but in most mammalian species mitochondria are closely located around the MII spindle $[50,52]$. This localization implies that they are important for spindle formation and maintenance of spindle integrity.

Meiotic spindle formation begins in most mammals at the center of the oocyte (reviewed in [53]) after nuclear envelope breakdown of the germinal vesicle (GVBD). This process of GVBD is triggered through stimulation of the cumulus cells by luteinizing hormone (LH). Perinuclear accumulation of mitochondria is a positive sign of oocyte quality and allows accurate timing of GVBD (reviewed in [53]). The formed spindle migrates to the oocyte cortex and is anchored to the cortex by an actin filament cap (reviewed in [53]).

Oocyte maturation is important for the establishment of oocyte qualities that allow for optimal fertilization and embryo development. During oocyte maturation, the oocyte grows and undergoes remodeling on cellular and molecular levels. This remodeling requires ATP likely supplied by mitochondria; thereby allowing timely and accurate cytoplasmic and nuclear maturation [54]. Mitochondriasupplied ATP is also important for protein phosphorylation and dephosphorylation which are among the regulatory events that play key roles in oocyte maturation, and include centrosome and microtubule dynamics for the formation of the meiotic spindles during meiosis I (MI) and II (MII) [18,19,53,55-57]. Formation of the MI and MII spindle is a critical process to allow accurate chromosome segregation and the two successive asymmetric cell divisions that result in small polar bodies and a large polarized oocyte. The cytoskeleton plays important roles in this cellular and molecular remodeling, and it is essential for accurate redistribution of mitochondria throughout the maturation process [53,54,56,58-61].

The oocyte arrested at the MII stage is the final product of oocyte maturation. On average, the mature mammalian MII oocyte contains approximately 100,000 to 200,000 mtDNA copies [62] and amounts to almost 300,000 in pig oocytes [63]. The number of mtDNA in

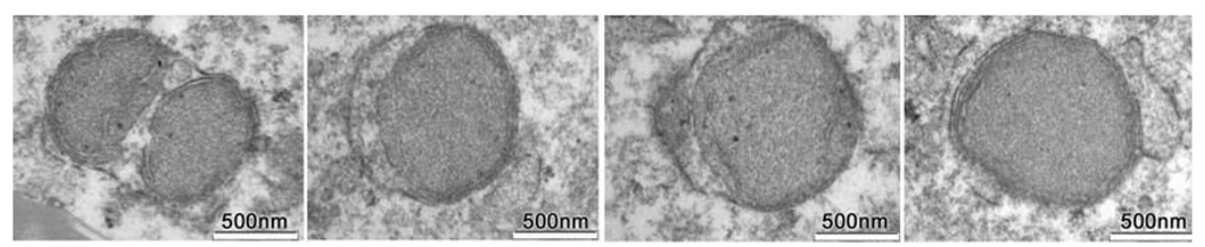

Figure 1 TEM of mitochondria. TEM of round mitochondria without cristae in 2-cell stage porcine oocyte at $48 \mathrm{~h}$ of in vitro fertilization. From Zhong et al. [4]. 
an oocyte is positively correlated with fertilization- and developmental- competence. Other indicators for positive developmental potential are the distribution of mitochondria surrounding the MII spindle in most mammals and positive staining with Brilliant Cresyl Blue (BCB). The BCB dye can be broken down by glucose-6phosphate dehydrogenase (G6PD) and can thus be used as an indicator of G6PD activity. BCB has been used reliably to determine oocyte quality [64]. G6PD is synthesized and accumulated during the oocyte growth phase; it is a rate limiting enzyme needed for NADPH production through the PPP. The different levels of $\mathrm{BCB}$ indicate variations in oocyte quality as estimated by G6PD. Oocytes with insufficient G6PD to reduce the dye, stain blue and are less likely to be developmentally competent, while oocytes not staining blue contain G6PD and reduce the dye to a colorless solution, indicating that these oocytes may be more developmentally competent. Other indicators for oocyte quality have also been used and have been reviewed in $[65,66]$.

Functional motor proteins and protein kinases that are needed for meiotic spindle assembly and chromosome alignment require ATP [16], and insufficient ATP production is associated with spindle abnormalities. Both meiotic divisions are error-prone in humans and chromosomal aneuploidies have been reported for the first and for the second meiosis [18,19,67-70]. Aberrant functions of motor proteins and kinetochore-related kinases may contribute to chromosomal aneuploidies in females with qualitycompromised oocytes [71]. Abnormalities in polo-like kinase (Plk) functions also have been implicated in aneuploidy. Since ATP is required for the function of protein kinases, low kinase activity may result in mitochondrial dysfunction $[8,72,73]$.

Fertilization: When the MII oocyte is ovulated it enters the oviduct where fertilization occurs. Fertilization initiates completion of meiosis II and is marked by extrusion of the second polar body (PBII) to achieve the haploid maternal contribution to the oocyte.

Mitochondria are maternally inherited in mammalian embryos, and the MII oocyte contains all mitochondria for subsequent development to the blastocyst stage [74]. The sperm's mitochondria are destroyed during the fertilization process [75,76] and the oocyte's immature mitochondria are distributed equally to the dividing daughter cells during first and subsequent cell divisions. Unequal distribution leads to disproportional patterns of mitochondrial inheritance [77] in 2- to 4-cell stage human embryos resulting in cell lysis of the blastomere that is deficient in mitochondria. Loss of cells from the developing embryo may have negative consequences for embryo implantation.

Preimplantation embryo development: Remodeling of mitochondrial features is important for differentiation when increased energy is needed for embryo development. During preimplantation embryo development several changes take place in mitochondrial architecture as they transform from a simple spherical structure to begin displaying more complex morphologies, including welldeveloped cristae, a denser matrix, and an elongated or branched appearance. This more complex change in morphology is correlated with a bioenergetic transition from mainly glycolytic to aerobic OXPHOS metabolism. This transition includes an increase in the respiratory chain complex density and ATP production. Several proteins drive the mitochondrial differentiation process which have been determined to some extent $[1,2]$ but many remain undetermined. As cellular differentiation occurs mitochondrial differences are especially apparent during blastocoel formation when cells are differentiated into trophectoderm (TE) and inner cell mass (ICM) cells $[1,2,78,79]$. Mitochondrial elongation and increased cristae formation is first observed in TE cells during their differentiation into an epithelial layer $[49,51,78]$ while ICM cells retain spherical mitochondria that contain only few or no cristae. The spherical shape in ICM cells is also characteristic for pluripotent stem cells and many cancer cell types.

Many of the studies on maturation, fertilization and embryo development have been performed in animal models such as the mouse, rabbit, bovine, and porcine systems and fewer studies are available for human; although this area of research is progressing more rapidly now because of the need for higher success rates in IVF clinics.

\section{Section 2: mitochondrial dysfunction in quality- compromised oocytes}

As mentioned in section 1, oocyte quality is important for fertilization and development into viable offspring. Qualitycompromised oocytes are correlated with infertility, developmental disorders, reduced blastocyst cell number and embryo loss, but the mechanisms underlying these effects are not well understood. Oocyte quality is achieved during the maturation process as addressed in section 1. Maturation defects can have several causes and many have been associated with mitochondrial dysfunction $[18,19]$ due to insufficient ATP, calcium homeostasis, hormonal effects, and several others.

Several metabolic changes or disorders such as obesity, diabetes, and aging among others, play a role in reduced oocyte quality. Metabolic disorders not only affect oocytes in the adult female but they also affect all oocytes produced in the developing fetus during pregnancy of the mother, as the adverse intrauterine environment directly affects oogenesis in the fetus and the embryo's primordial germ cells from which the next generation develops [80]. 
As mentioned in section 1 sufficient oocyte maturation, both nuclear and cytoplasmic, is important to acquire fertilization-competency (reviewed in [18]. Mitochondria are essential for cytoplasmic maturation to contribute ATP (reviewed in [81]) which is needed for critical cytoplasmic and cellular functions [82]. For effective cytoplasmic maturation a minimum amount of mitochondrial DNA (mtDNA) copy number is important; this has been demonstrated for mouse oocytes [83], bovine oocytes [84], porcine oocytes [64] and human oocytes [62]. While the copy numbers in mouse, bovine and porcine oocytes does not vary significantly between individual oocytes of the same species, interestingly, in the human, there is significant variability ranging between 20,000 and 598,000, with a mean of 193,000 [62], mean values of 256,000 [85], 314,000 [86] and mean values of 795,000 [87] copies. This significant range in human oocytes may reflect the range of different IVF patients analyzed, and it may be indicative of the wide range of oocyte quality in humans that may be correlated with fertility and decreased fertility/infertility problems [88]. A threshold level of mtDNA is necessary to support fertilization and embryo development $[64,83]$. As all mitochondria are maternally inherited (reviewed in $[18,19])$ the threshold number of mitochondria in the metaphase II (MII) oocyte is critical. The regulation of oocyte mDNA copy number has been studied in detail by Mao et al. [63]) and it has been shown that follicular fluid, epidermal growth factor (EGF) and neuroregulin 1 play a significant role during in vitro maturation and subsequent embryo development in pigs.

Oocyte aging is strongly associated with mitochondrial dysfunction $[6,8,13,17]$ for which underlying causes have been explored and include: an increase in mtDNA damage with changes in copy number and mutational load; changes in mitochondrial gene expression; a decrease in mitochondrial membrane potential; changes in mitochondrial dynamics; increased density of mitochondrial matrix; frequency of ruptured mitochondrial membranes; a decrease in $\Delta \varphi_{\mathrm{m}}$, a decrease in ATP synthesis and metabolic reactions in the electron transport chain; and increased production of reactive oxygen species (ROS). The excessive reactive oxygen species (ROS) generation is closely associated with the oxidative energy production or calcium overload, which may trigger opening of the transition pore and subsequent apoptosis.

ROS is generated during the production of ATP and it causes oxidative damage to mitochondrial DNA if not detoxified, which results in mutations and deletions of mtDNA. As repair enzymes for mtDNA are minimal, mitochondria are especially sensitive to oxidative stressinduced damage [89]. The mutation rate in mitochondrial DNA is 10- to 20-fold higher compared with nuclear DNA, and it is likely related to the limited DNA repair capacity [90,91]. A number of different mitochondrial deletions and mutations have been reported and the most common deletion has been identified in the human mitochondrial genome as a 4,977 bp deletion within two $13 \mathrm{bp}$ repeats, beginning at positions 8,470 and ending at 13,459 [92]. The accumulation of the 4,977 bp deletion within mtDNA is considered a marker for aging [85,93-95] and is related to lower energy production. Accumulations of mutational loads to the mtDNA adversely affects mitochondrial functions and will negatively impact development of the preimplantation embryo. In addition, oocyte mitochondria with mutations may pass these mutations to the offspring who will inherit the susceptibility to metabolic diseases [96,97].

Chromosomal aneuploidies are well known effects of oocyte aging but the time-dependent detailed cascades and specific mechanisms leading to loss of spindle integrity and aneuploidy are still being explored. A detailed cause and effect mechanism is not known. However, several aspects are clearly observed during the aging process and include decreases in motor protein functions as addressed above in section 1 .

Diabetes and obesity are two of the major causes for mitochondrial dysfunction [3,11,12,98-100] which has significant implications for oocyte quality from women with such metabolic disorders or diseases [3,10-12,100-102]. Other dysfunctions related to metabolic disorders are probable but many dysfunctions remain unexplained.

Diabetes and obesity have become major concerns worldwide and have now exceeded the undernourished population with estimated numbers of 1.5 billion and 1 billion, respectively. Diabetes and obesity are both significantly associated with infertility and have contributed to the increase in patients seeking ART procedures in IVF clinics. Many of the mitochondrial dysfunctions that are known for aging oocytes are also seen in oocytes from diabetic and obese females: these include a decrease in membrane potential, reduced blastocyst formation with imbalances in TE and ICM cell numbers resulting in embryo loss, and several others; reviewed in $[3,11,12,100,103]$.

\section{Section 3: possibilities to overcome mitochondrial dysfunction in oocytes to improve IVF success rates}

One of the most challenging obstacles for achieving successful in vitro fertilization (IVF) and embryo development in IVF clinics is the poor quality of mitochondria in oocytes of obese and diabetic women, of women at advanced reproductive ages, and of women with various other metabolic disorders. This limitation has stimulated a number of different approaches to overcome the defects and includes cytoplasmic transfer which refers to the supplementation of an oocyte with donor cytoplasm containing healthy mitochondria (mitochondrial supplementation). 
While this approach had raised concerns as mentioned in the introduction [26] cytoplasmic transfer has recently been viewed more favorably as an optional therapy to eliminate mitochondrial mutations, thereby allowing the birth of mitochondrial mutation-free healthy children [27-29]. However, there are risks to be taken into account. For example, in ooplasmic transfer, of 13 pregnancies, two fetuses were karyotypically 45, XO (Turner's syndrome). One of these fetuses aborted spontaneously and the other pregnancy was terminated. This fact is recorded in a FDA document (http://www.fda.gov/OHRMS/DOCKETS/ ac/02/briefing/3855B1_01.doc). While different policies exist in different countries [104] and research is not supported by Federal funding agencies clinical applications are possible. The option is available if parents agree to the procedure. With these new considerations $[105,106]$ new approaches for cytoplasmic transfer into qualitycompromised oocytes are possible to overcome mitochondrial dysfunctions or deficiencies. Such procedures are especially important considering that the demand for IVF procedures has increased significantly in recent years. The increase in demand is in part due to the worldwide increases in obesity, diabetes and the trend to have children later in life when oocytes have aged considerably and display mitochondrial insufficiencies $[8,9,12,88,107]$. New treatment options for quality-compromised oocytes are needed to overcome insufficient mitochondrial functions.

Because many developmental disorders and diseases are associated with dysfunctional mitochondria (such as neurological diseases [108,109], diabetes [99,110] and references therein, cancer [111], the immune system [112] and aging [113], as well as other diseases and disorders that affect a large percent of the population worldwide) research on mitochondria has excelled in recent years. Since mitochondria are versatile and can be manipulated experimentally it is possible to develop new strategies for therapeutic intervention to restore mitochondrial functions once we know the specific defects [36].
In quality-compromised oocytes containing dysfunctional mitochondria transfer of mitochondria-containing cytoplasm from donated fresh oocytes has corrected the mitochondrial lesions [6,26-29]. The benefits, but also complexities, have been addressed and it was shown that the source of the donor cytoplasm is a major factor in successes or failures. Because of the close functional dependency of mitochondria on the nuclear genome the cell type used for donor transfer is of primary concern and should be closely related to the recipient cell for optimal coordination of mtDNA and nuclear DNA. Ovarian or oocyte-differentiated cells have been shown to yield the highest success rate in transferring donor cytoplasm containing healthy mitochondria into qualitycompromised oocytes. Cells of oogonial derivation have been studied in recent years in light of the search for oogonial stem cells or stem-like cells [114-118] for which unresolved controversies exist in the field [119]. However, this research has benefitted the characterization of oogonial-derived cells.

Germ line quality mitochondria are optimally available from oocyte precursor cells and may be used preferably to reduce possible compromised oxidative phosphorylation function that may be encountered as a result of mitochondrial heteroplasmy (mixing of different mtDNA genotypes) $[64,120]$. Heteroplasmy might be a problem and may cause negative effects but it has also has been shown in somatic cell nuclear transfer (SCNT) experiments that heteroplasmy is tolerable to some extent [121] (Figures 2 and 3). In women with 3\% of mtDNA heteroplasmy no negative effects are observed [122] (Figure 4). The possibility of oocyte precursor cells has been reported in both the mouse and human [123-129]. These cells might serve as excellent mitochondria donors as they have differentiated to the oocyte lineage without having resided for prolonged times in a postmitotic state and would fulfill the optimal conditions to provide high-quality germ line autologous homoplasmic

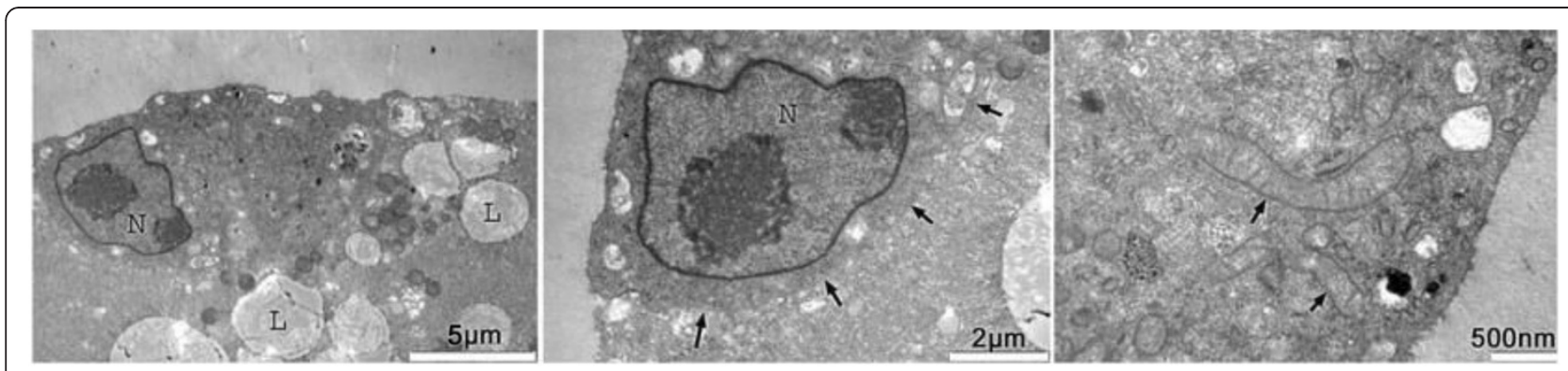

Figure 2 TEM of mitochondria after SCNT. TEM of reconstructed (somatic nuclear transfer; SCNT) oocyte at 30 min after fusion. The donor cell is still clearly separated from the enucleated oocyte (delineated by arrows) at this stage of SCNT. These cells contain somatic cell mitochondria with an elongated shape and cristae that co-exist with round oocyte mitochondria for at least up to the blastocyst stages and represent heteroplasmy in the developing pre-implantation embryo. From Zhong et al. [4]. 


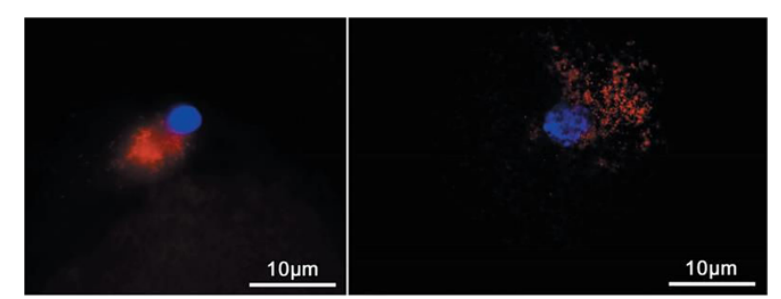

Figure 3 Fluorescence microscopy of mitochondria after SCNT. Fluorescence microscopy of donor cell preloaded with CMXRos, 30 min after fusion of donor cell into enucleated oocyte. Donor-derived mitochondria locate near the donor nucleus and disperse into the cytoplasm in developing embryos with heteroplasmy as observed up to the blastocyst stages. From Zhong et al. [4].

mitochondrial DNA without containing mutations and deletions [122].

Considering that numerous mitochondrial mutations, deletions, and nucleotide variations are found in qualitycompromised oocytes and blastocysts [130] from women of advanced ages and women with metabolic disorders, such as obesity or diabetes new treatments to augment the healthy mitochondrial population through cytoplasmic transfer from uncompromised cells would not only benefit the mothers to overcome fertility problems but

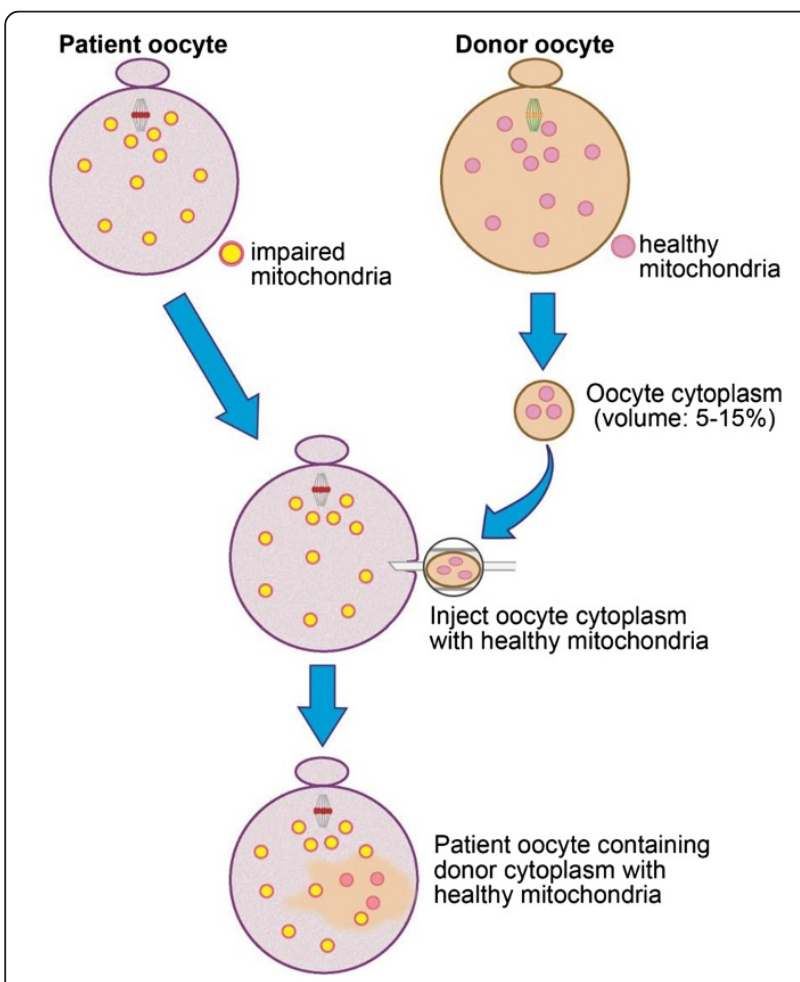

Figure $\mathbf{4}$ Schematic diagram of mitochondrial supplementation. Ooplasmic mitochondrial transfer (schematic diagram). A patient's oocyte containing inferior mitochondria is injected with donor into the patient's oocyte to supplement the mitochondrial population required for normal development. From Yabuuchi et al. [122]. also children of affected mothers who otherwise may inherit mitochondria with deficiencies and suboptimal function. In many cases a low amount of mitochondrial transfer is sufficient to restore optimal mitochondria function and prevent inheritance of suboptimal mitochondria to the next generation.

Other sources for mitochondrial transfer may include stem cell cytoplasm, as stem cell mitochondria display many of the characteristics that are known for embryonic immature mitochondria (reviewed in $[1,7]$ including the round shapes, glycolysis for energy generation, and amenability to differentiation under different environmental conditions.

Aside from cytoplasmic transfer dietary aspects (such as dietary supplementation with CoQ10 that may increase mitochondrial activity) have also been considered to improve mitochondria functions in quality-compromised oocytes [131]. CoQ10 aids in the transport of electrons in the mitochondrial respiratory chain and is therefore a key enzyme in energy production. Other therapies are being considered and a variety of approaches have been proposed to develop strategies for mitochondrial pharmacology leading to the identification of druggable mitochondrial targets [36].

Different from approaches to supplement mitochondria through cytoplasmic transfer are the approaches that are currently being discussed to eliminate inherited mtDNA mutations. To eliminate the transmission of mtDNA mutations to the offspring two oocytes from different females are needed and several approaches are possible.

In one approach either the GV or the MII spindle and associated chromosomes are removed from the patient's unfertilized egg containing the abnormal mitochondria and transferred into an enucleated donor egg containing healthy mitochondria. The donor egg now primarily contains the donor's mitochondrial DNA but the patient's nuclear DNA although some of the patient's mitochondrial DNA is transferred along with the nucleus. This reconstituted egg now can be fertilized with the patient's partner through the intracytoplasmic sperm injection (ICSI) procedure; thereby now containing the future parents' nuclear DNA but mitochondria from the donor. The cleaving embryo with normal mitochondria and maternal and paternal genomes can then be transplanted into the patient's uterus. This approach has also been characterized as "three-parent in vitro fertilization" but in fact the nuclear genetic material is only contributed by two parents. It is primarily used to prevent transmission of inherited mitochondria disease. This approach has been discussed extensively during the past year and resulted in approval by the Food and Drug Administration (FDA) [106]. It had previously been evaluated in 2012 by the UK Human Fertilization and 
Embryology Authority (HFEA) [104]. Details of this procedure are described in several recent papers including [26,28-31,122,132,133].

In another approach the patient's egg containing abnormal mitochondria is fertilized with the partner's sperm and allowed to develop to the patient's zygote stage that still contains the abnormal mitochondria. The patient's pronuclei are then removed and transferred to an enucleated donor egg containing healthy mitochondria. The reconstructed zygote is then processed further for transfer into the patient's uterus.

In a more recent approach the recipient oocyte is enucleated by removing the MII spindle; a donor oocyte is fertilized and the second polar body is removed and then transferred to the recipient oocyte [134], now containing the donor oocyte's nuclear DNA but minimal amounts of mitochondria, as the polar body only contains a small amount of mitochondria and mainly consists of one chromosome set that is extruded naturally to restore the haploid oocyte condition as detailed in section 1 . The second polar body contains the same amount of nuclear DNA as the oocyte. The recipient oocyte with healthy mitochondria now contains the nuclear DNA of the donor and can then be used for IVF following regular IVF procedures. Variations of these current procedures are possible to eliminate transmission of mutant mtDNA to children and will allow the generation of children without inheriting mitochondrial diseases from affected parents.

Other therapeutic approaches are actively being pursued to improve mitochondrial dysfunction and include approaches based on genome editing. For example, specific elimination of mutant mitochondrial genomes in patient-derived cells by mitoTALENs have been reported [135] in which mitochondria-targeted TALEN expression led to permanent reductions in deletion or pointmutant mtDNA in patient-derived cells.

\section{Perspectives and future directions}

The past decade has seen enormous advances in potential therapies for quality-compromised oocytes that will particularly benefit women with metabolic disorders such as obesity, or diseases such as diabetes, or metabolic changes associated with aging. Dietary components such as CoQ10 and especially transfer of mitochondria from cells with mitochondrial integrity have opened new possibilities for therapeutic advances which will increase the success rates for oocytes of women with compromised oocyte quality. Optimal conditions for such transfers include that mitochondrial supplementation should be obtained from the patient's own cells for optimal communication between mtDNA and nuclear DNA to maintain homoplasmy in offspring; using cells of ovarian or oocyte origin; and using mitochondria of high-quality cells without the risk to transmit deletions or mutations to the offspring. Stem cell mitochondria may be an optimal source for supplementation of quality-compromised oocytes.

\section{Competing interests}

The authors declare that they have no competing interests.

\section{Authors' contributions}

All authors participated and contributed to the writing of this manuscript. All authors read and approved the final manuscript.

\section{Author details}

${ }^{1}$ Department of Veterinary Pathobiology, University of Missouri, Columbia, MO, USA. ${ }^{2}$ State Key Laboratory of Reproductive Biology, Institute of Zoology, Chinese Academy of Sciences, Beijing 100080, China. ${ }^{3}$ National Swine Resource and Research Center, University of Missouri, Columbia 65211, USA. ${ }^{4}$ Division of Animal Science, University of Missouri, Columbia 65211, USA.

Received: 17 July 2014 Accepted: 4 September 2014

Published: 24 November 2014

\section{References}

1. Krisher RL, Prather RS: A role for the Warburg effect in preimplantation embryo development: metabolic modification to support rapid cell proliferation. Mol Reprod Devel 2012, 79(5):311-320.

2. Redel BK, Brown AN, Spate LD, Whitworth KM, Green JA, Prather RS: Glycolysis in preimplantation development is partially controlled by the Warburg Effect. Mol Reprod Devel 2012, 79:262-271.

3. Wang Q, Ratchford AM, Chi MM, Schoeller E, Frolova A, Schedl T, Moley KH: Maternal diabetes causes mitochondrial dysfunction and meiotic defects in murine oocytes. Mol Endocrinol 2009, 23(10):1603-1612.

4. Zhong Z, Hao Y, Li R, Spate L, Wax D, Sun Q-Y, Prather RS, Schatten H: Analysis of heterogeneous mitochondria distribution in somatic cell nuclear transfer porcine embryos. Microsc Microanal 2008, 14(5):418-432.

5. Wakefield SL, Lane M, Mitchell M: Impaired mitochondrial function in the preimplantation embryo perturbs fetal and placental development in the mouse. Biol Reprod 2011, 84:572-580.

6. Chappel S: The role of mitochondria from mature oocyte to viable blastocyst. Obstet Gynecol Internat 2013, 2013(1):1-10.

7. Schatten H, Sun Q-Y, Prather RS: Mitochondrial differentiation in early embryo cells and pluripotent stem cells. In Cell and Molecular Biology and Imaging of Stem Cells. Heide Schatten. Hoboken: Wiley; 2014. in press.

8. Wang ZB, Schatten $\mathrm{H}$, Sun QY: Why is chromosome segregation error in oocytes increased with maternal aging? Physiology 2011, 26(5):314-325.

9. Qiao J, Wang ZB, Feng HL, Miao YL, Wang Q, Yu Y, Wei YC, Yan J, Wang WH, Shen W, Sun SC, Schatten H, Sun QY: The root of reduced fertility in aged women and possible therapeutic options: Current status and future perspectives. Mol Aspects Medicine 2014, 38:54-85.

10. Moley KH, Chi MM, Mueckler MM: Maternal hyperglycemia alters glucose transport and utilization in mouse preimplantation embryos. Am J Physiol 1998, 275:E38-E47.

11. Ou XH, Li S, Wang ZB, Li M, Quan S, Xing F, Guo L, Chao SB, Chen Z, Liang XW, Hou Y, Schatten $H$, Sun QY: Maternal insulin resistance causes oxidative stress and mitochondrial dysfunction in mouse oocytes. Human Reprod 2012, 27(7):2130-2145.

12. Zhang $C H$, Qian WP, Qi ST, Ge ZJ, Min LJ, Zhu XL, Huang X, Liu JP, Ouyang YC, Hou Y, Schatten H, Sun QY: Maternal diabetes causes abnormal dynamic changes of endoplasmic reticulum during mouse oocyte maturation and early embryo development. Reprod Biol Endocrinol 2013, 11:31

13. Miao Y, Kikuchi K, Schatten H, Sun Q-Y: Oocyte aging: cellular and molecular changes, developmental potential and reversal possibility. Human Reprod Update 2009, 15(5):573-585.

14. Ge H, Tollner TL, Hu Z, Dai M, Li X, Guan H, Shan D, Zhang X, Lv J, Huang C, Dong Q: The importance of mitochondrial metabolic activity and mitochondrial DNA replication during oocyte maturation in vitro on oocyte quality and subsequent embryo developmental competence. Mol Reprod Dev 2012, 79(6):392-401.

15. Ge ZJ, Liang XW, Guo L, Liang QX, Luo SM, Wang YP, Wei YC, Han ZM, Schatten H, Sun QY: Maternal Diabetes Causes Alterations of DNA 
Methylation Statuses of Some Imprinted Genes in Murine Oocytes. Biol Reprod 2013, 88(5):117. 1-9.

16. Eichenlaub-Ritter U: Genetics of oocyte ageing. Maturitas 1998, 30(2):143-169.

17. Eichenlaub-Ritter U, Wieczorek M, Lüke S, Seidel T: Age related changes in mitochondrial function and new approaches to study redox regulation in mammalian oocytes in response to age or maturation conditions. Mitochondrion 2011, 11:783-796.

18. Schatten H, Sun QY: New insights into the role of centrosomes in mammalian fertilisation and implications for ART. Reproduction 2011, 142:793-801.

19. Schatten $H$, Sun QY: Centrosome dynamics during meiotic spindle formation in oocyte maturation. Mol Reprod Devel 2011, 78:757-768.

20. Pellestor F, Anahory T, Hamamah S: Effect of maternal age on the frequency of cytogenetic abnormalities in human oocytes. Cytogen Genome Res 2005, 111(3-4):206-212.

21. Hassold T, Hunt P: To err (meiotically) is human: The genesis of human aneuploidy. Nat Rev Genet 2001, 2:280-291.

22. Cohen J, Scott R, Alikani M, Schimmel T, Munné S, Levron J, Wu L, Brenner C, Warner C, Willadsen S: Ooplasmic transfer in mature human oocytes. Mol Hum Reprod 1998, 4(3):269-280.

23. Yi YC, Chen MJ, Ho JY, Guu HF, Ho ES: Mitochondria transfer can enhance the murine embryo development. J Assist Reprod Genet 2007, 24(10):445-449.

24. Malter $\mathrm{HE}$, Cohen J: Ooplasmic transfer: animal models assist human studies. Reprod Biomed Online 2002, 5(1):26-35.

25. Schon EA, DiMauro S, Hirano M, Gilkerson RW: Therapeutic prospects for mitochondrial disease. Trends Mol Med 2010, 16(6):268-276.

26. Reinhardt K, Dowling DK, Morrow EH: Mitochondrial replacement, evolution, and the clinic. Science 2013, 341(6152):1345-1346.

27. Smeets HJM: Preventing the transmission of mitochondrial DNA disorders: Selecting the good guys or kicking out the bad guys. Reprod BioMed Online 2013, 27:599-610.

28. Amato $P$, Tachibana M, Sparman M, Mitalipov: Three-parent in vitro fertilization: gene replacement for the prevention of inherited mitochondrial diseases. Fertil Steril 2014, 101(1):31-35.

29. Mitalipov S, Wolf DP: Clinical and ethical implications of mitochondrial gene transfer. Trends Endocrinol Metab 2014, 25(1):5-7.

30. Chinnery PF, Craven L, Mitalipov S, Stewart JB, Herbert M, Turnbull DM: The challenges of mitochondrial replacement. PLOS Genet 2014 10(4):e1004315.

31. Moraes CT, Bacman SR, Williams SL: Manipulating mitochondrial genomes in the clinic: playing by different rules. Trends Cell Biol 2014, 24(4):209-211.

32. Jacobson J, Duchen MR: Interplay between mitochondria and cellular calcium signaling. Mol Cell Biochem 2004, 256/257:209-218.

33. Danial NN, Korsmeyer SJ: Cell death: critical control points. Cell 2004 116:205-219.

34. Dyall SD, Brown MT, Johnson PJ: Ancient invasions: from endosymbionts to organelles. Science 2004, 304:253-257.

35. Detmer SA, Chan DC: Functions and dysfunctions of mitochondrial dynamics. Nat Rev Mol Cell Biol 2007, 8:870-879.

36. Smith PM, Fox JL, Winge DR: Biogenesis of the cytochrome bc(1) complex and role of assembly factors. Biochim Biophys Acta 1817, 2012:276-286.

37. Anderson S, Bankier AT, Barrel BG, de Bruijn MH, Coulson AR, Drouin J, Eperon IC, Nierlich DP, Roe BA, Sanger F, Schreier PH, Smith AJH, Staden R, Young IG: Sequence and organization of the human mitochondrial genome. Nature 1981, 290:457-465.

38. St John JC, Facucho-Oliveira J, Jiang Y, Kelly R, Salah R: Mitochondrial DNA transmission, replication and inheritance: a journey from the gamete through the embryo and into offspring and embryonic stem cells. Human Reprod Update 2010, 16(5):488-509.

39. Takasugi M, Yagi S, Hirabayashi K, Shiota K: DNA methylation status of nuclear-encoded mitochondrial genes underlies the tissue-dependent mitochondrial functions. BMC Genomics 2010, 11(1):481-489.

40. Balaban RS: The mitochondrial proteome: a dynamic functional programing tissues and disease states. Environ Mol Mutagen 2010, 51(5):352-359.

41. Larsson NG, Wang J, Wilhelmsson H, Oldfors A, Rustin P, Lewandoski M, Barsh GS, Clayton DA: Mitochondrial transcription factor $A$ is necessary for mtDNA maintenance and embryogenesis in mice. Nat Genet 1998 18:231-236.

42. Antelman J, Manandhar G, Yi YJ, Li R, Whitworth KM, Sutovsky M, Agca C, Prather RS, Sutovsky P: Expression of mitochondrial transcription factor A
(TFAM) during porcine gametogenesis and preimplantation embryo development. J Cellular Physiol 2008, 217(2):529-543.

43. Gray $H$, Wong TW: Purification and identification of subunit structure of the human mitochondrial polymerase. J Biol Chem 1992, 267:5835-5841.

44. Crompton M: The mitochondrial permeability transition pore and its role in cell death. Biochem J 1999, 341(2):233-249.

45. Bernardi $P$ : The mitochondrial permeability transition pore: a mystery solved? Frontiers Physiol 2013, 4, Article 95(1):1-12.

46. Hom JR, Quintanilla RA, Hoffman DL, de Mesy Bentley KL, Molkentin JD, Sheu SS, Porter GA Jr: The permeability transition pore controls cardiac mitochondrial maturation and myocyte differentiation. Dev Cell 2011, 21(3):469-478.

47. Wilding M, Dale B, Marino M, di Matteo L, Alviggi C, Pisaturo ML, Lombard $\mathrm{L}$, de Placido $\mathrm{G}$ : Mitochondrial aggregation patterns and activity in human oocytes and preimplantation embryos. Hum Reprod 2001, 16(5):909-917

48. Zhang YZ, Ouyang YC, Hou Y, Schatten H, Chen DY, Sun QY: Mitochondrial behavior during oogenesis in zebrafish: a confocal microscopy analysis. Dev Growth Differ 2008, 50(3):189-201.

49. Sun Q-Y, Wu GM, Lai L, Park KW, Day B, Prather RS, Schatten H: Translocation of active mitochondria during pig oocyte maturation, fertilization and early embryo development in vitro. Reproduction 2001, 122:155-163.

50. Katayama M, Zhong Z-S, Lai L, Sutovsky P, Prather RS, Schatten H: Mitochondria distribution and microtubule organization in fertilized and cloned porcine embryos: Implications for developmental potential. Dev Biol 2006, 299:206-220.

51. Schatten H, Prather RS, Sun Q-Y: The significance of mitochondria for embryo development in cloned farm animals. Mitochondrion 2005, 5:303-321.

52. Calarco PG: Polarization of mitochondria in the unfertilized mouse oocytes. Dev Genet 1995, 16:36-46.

53. Ai J-S, Li M, Schatten H, Sun Q-Y: Regulatory mechanism of spindle movements during oocyte meiotic division. Asian Aust J Anim Sci 2009, 22:1447-1486.

54. Sirard MA, Richard F, Blondin P, Robert C: Contribution of the oocyte to embryo quality. Theriogenol 2006, 65:126-136.

55. Swain JE, Pool TB: ART failure: Oocyte contributions to unsuccessful fertilization. Hum Reprod Update 2008, 14:431-446.

56. Fan H-Y, Liu Z, Shimada M, Sterneck E, Johnson PF, Hedrick S, Richards JS: MAPK3/1 (ERK1/2) in ovarian granulosa cells are essential for female fertility. Science 2009, 324:938-941.

57. Gosden R, Lee B: Portrait of an oocyte: Our obscure origin. J Clin Invest 2010, 120:973-983.

58. Fan HY, Huo L, Meng XQ, Zhong ZS, Hou Y, Chen DY, Sun QY: Involvement of calcium/calmodulin-dependent protein kinase II (CaMKII) in meiotic maturation and activation of pig oocytes. Biol Reprod 2003, 69:1552-1564

59. Voronina E, Wessel GM: The regulation of oocyte maturation. Curr Top Dev Biol 2003, 58:53-110.

60. Brunet S, Maro B: Cytoskeleton and cell cycle control during meiotic maturation of the mouse oocyte: Integrating time and space. Reproduction 2005, 130:801-811.

61. Liang $C-G$, Su Y-Q, Fan H-Y, Schatten $H$, Sun Q-Y: Mechanisms regulating oocyte meiotic resumption: Roles of mitogen-activated protein kinase. Mol Endocrinol 2007, 21:2037-2055.

62. Reynier P, May-Panloup P, Chretien MF, Morgan CJ, Jean M, Savagner F, Barriere $P$, Malthiery $Y$ : Mitochondrial DNA content affects the fertilizability of human oocytes. Mol Human Reprod 2001, 7:425-429.

63. Mao J, Whitworth KM, Spate LD, Walters EM, Zhao J, Prather RS: Regulation of oocyte mitochondrial DNA copy number by follicular fluid, EGF, and neuregulin 1 during in vitro maturation affects embryo development in pigs. Theriogenology 2012, 78:887-897.

64. El Shourbagy SH, Spikings EC, Freitas M, St John JC: Mitochondria directly influence fertilisation outcome in the pig. Reprod 2006, 131(2):233-245.

65. Ola SI, Sun Q-Y: Factors influencing the biochemical markers for predicting mammalian oocyte quality. J Reprod Dev 2012, 58(4):385-392.

66. Wang Q, Sun QY: Evaluation of oocyte quality: morphological, cellular and molecular predictors. Reprod Fertil Dev 2007, 19(1):1-12.

67. Robertson JA: Oocyte cytoplasm transfers and the ethics of germ-line intervention. J. Law Med Ethics 1998, 26(3):211-220. 179.

68. Chiang T, Schultz RM, Lampson MA: Meiotic origins of maternal agerelated aneuploidy. Biol Reprod 2012, 86:1-7. 
69. Fragouli E, Alfarawati S, Goodall NN, Sánchez-Garcıa JF, Colls P, Wells D: The cytogenetics of polar bodies: insights into female meiosis and the diagnosis of aneuploidy. Mol Human Reprod 2011, 17(5):286-295

70. Handyside AH, Montag M, Magli MC, Repping S, Harper J, Schmutzler A, Vesela K, Gianaroli L, Geraedts J: Multiple meiotic errors caused by predivision of chromatids in women of advanced maternal age undergoing in vitro fertilization. Eur J Human Genetics 2012, 20:742-747.

71. Yin H, Baart E, Betzendahl I, Eichenlaub-Ritter U: Diazepam induces meiotic delay, aneuploidy and predivision of homologues and chromatids in mammalian oocytes. Mutagenesis 1998, 13(6):567-580.

72. Golsteyn RM, Schultz SJ, Bartek J, Ziemiecki A, Ried T, Nigg EA: Cell cycle analysis and chromosomal localization of human Plk1, a putative homologue of the mitotic kinases Drosophila polo and Saccharomyces cerevisiae Cdc5. J Cell Sci 1994, 107(6):1509-1517.

73. Pahlavan G, Polanski Z, Kalab P, Golsteyn R, Nigg EA, Maro B: Characterization of polo-like kinase 1 during meiotic maturation of the mouse oocyte. Dev Biol 2000, 220(2):392-400.

74. Luo SM, Ge ZJ, Wang ZW, Jiang ZZ, Wang ZB, Ouyang YC, Hou Y, Schatten $\mathrm{H}$, Sun QY: Unique insights into maternal mitochondrial inheritance in mice. Proc Natl Acad Sci 2013, 110(32):13038-43.

75. Sutovsky P: Degradation of paternal mitochondria after fertilization: Implications for heteroplasmy, assisted reproductive technologies and mtDNA inheritance. Reprod Biol Med 2004, 8:24-33.

76. Luo SM, Schatten H, Sun QY: Sperm mitochondria in reproduction: good or bad and where do they go? I Genet Genomics 2013, 40(11):549-56

77. Van Blerkom J, Davis P, Alexander S: Differential mitochondrial distribution in human pronuclear embryos leads to disproportionate inheritance between blastomeres: relationship to microtubular organization, ATP content and competence. Hum Reprod 2000, 15(12):2621-2633.

78. Martin L, Besch-Williford C, Lai L, Cheong HT, Im GS, Park KW, Murphy C, Hao Y, Ellersieck MR, Keisler DH, Schatten H, Green JA, Prather RS: Morphologic and histologic comparisons between in vivo and nuclear transfer derived porcine embryos. Mol Reprod Dev 2007, 74(8):952-960.

79. Hall VJ, Jacobsen JV, Rasmussen MA, Hyttel P: Ultrastructural and molecular distinctions between the porcine inner cell mass and epiblast reveal unique pluripotent cell states. Dev Dyn 2010, 239(11):2911-2920

80. Fowden AL, Giussani DA, Forhead AJ: Intrauterine programming of physiological systems: causes and consequences. Physiology 2006, 21:29-37.

81. Sutton-McDowall ML, Gilchrist RB, Thompson JG: The pivotal role of glucose metabolism in determining oocyte developmental competence. Reproduction 2010, 139:685-695.

82. Moyes CD, Battersby BJ, Leary SC: Regulation of muscle mitochondrial designs. J Exp Biol 1998, 201:299-307.

83. Piko L, Taylor KD: Amounts of mtDNA and abundance of some mitochondrial gene transcripts in early mouse embryos. Dev Biol 1987, 123:364-374.

84. Michaels GS, Hauswirth WW, Laipis PJ: Mitochondrial DNA copy number in bovine oocytes and somatic cells. Dev Biol 1982, 94:246-251.

85. May-Panloup P, Chrétien MF, Jacques C, Vasseur C, Malthièry Y, Reynier P: Low oocyte mitochondrial DNA content in ovarian insufficiency. Human Reprod 2005, 20(3):593-597.

86. Steuerwald N, Barrit JA, Adler R, Malter H, Schimmel T, Cohen J, Brenner CA: Quantification of mtDNA in single oocytes, polar bodies and subcellular components by real-time rapid cycle fluorescence monitored PCR. Zygote 2000, 9:209-215.

87. Barritt JA, Kokot M, Cohen J, Steuerwald N, Brenner CA: Quantification of human ooplasmic mitochondria. Reprod Biomed Online 2002, 4:243-247.

88. Wang Q, Moley KH: Maternal diabetes and oocyte quality. Mitochondrion 2010, 10(5):403-410.

89. Larsson NG: Somatic mitochondrial DNA mutations in mammalian aging. Ann Rev Biochem 2010, 79:683-706.

90. Taylor RW, Barron MJ, Borthwick GM, Gospel A, Chinnery PF, Samuels DC Taylor GA, Plusa SM, Needham SJ, Greaves LC, Kirkwood TB, Turnbull DM: Mitochondrial DNA mutations in human colonic crypt stem cells. J Clin Investig 2003, 112(9):1351-1360.

91. Lee HC, Wei YH: Oxidative stress, mitochondrial DNA mutation, and apoptosis in aging. Exp Biol Med 2007, 232(5):592-606.

92. Shoffner JM, Lott MT, Voljavec AS, Soueidan SA, Costigan DA, Wallace DC Spontaneous Kearns-Sayre/chronic external ophthalmoplegia plus syndrome associated with a mitochondrial DNA deletion: a slip-replication model and metabolic therapy. Proc Natl Acad Sci 1989, 86(20):7952-7956.
93. Jacobs L, Gerards M, Chinnery P, Dumoulin J, de Coo I, Geraedts J, Smeets S: mtDNA point mutations are present at various levels of heteroplasmy in human oocytes. Mol Human Reprod 2007, 13(3):149-154.

94. Cortopassi GA, Arnheim N: Detection of a specific mitochondrial DNA deletion in tissues of older humans. Nucleic Acids Res 1990, 18(23):6927-6933.

95. Cortopassi GA, Shibata D, Soong NW, Arnheim N: A pattern of accumulation of a somatic deletion of mitochondrial DNA in aging human tissues. Proc Natl Acad Sci 1992, 89(16):7370-7374.

96. Van Blerkom J: Mitochondria in human oogenesis and preimplantation embryogenesis: engines of metabolism, ionic regulation and developmental competence. Reproduction 2004, 128(3):269-280.

97. Schaefer AM, McFarland R, Blakely EL, He L, Whittaker RG, Taylor RW, Chinnery PF, Turnbull DM: Prevalence of mitochondrial DNA disease in adults. Annals Neurol 2008, 63(1):35-39.

98. Adastra KL, Chi MM, Riley JK, Moley KH: A differential autophagic response to hyperglycemia in the developing murine embryo. Reproduction 2011, 141(5):607-615.

99. Yu L, Fink BD, Herlein JA, Sivitz Wl: Mitochondrial function in diabetes: novel methodology and new insight. Diabetes 2013, 62(6):1833-1842.

100. Ge ZJ, Zhang CL, Schatten H, Sun QY: Maternal diabetes mellitus and the origin of non-communicable diseases in offspring: the role of epigenetics. Biol Reprod 2014, 90(6):139. 1-6.

101. Igosheva N, Abramov AY, Poston L, Eckert JJ, Fleming TP, Duchen MR, McConnell J: Maternal diet-induced obesity alters mitochondrial activity and redox status in mouse oocytes and zygotes. PLoS One 2010, 5(4):e10074-e10082

102. Purcell SH, Moley KH: The impact of obesity on egg quality. J Assist Reprod Genetics 2011, 28:517-524.

103. Binder NK, Hannan NJ, Gardner DK: Paternal diet-induced obesity retards early mouse embryo development, mitochondrial activity and pregnancy health. PLoS One 2012, 7(12):e52304.

104. Ishii T: Potential impact of human mitochondrial replacement on global policy regarding germline gene modification. Reprod Biomed Online 2014, 29:150-155.

105. HFEA: Mitochondria public consultation 2012. In Mitochondria replacement consultation-advice for Government. http://www.hfea.gov.uk/6896.html.

106. FDA: Cellular Tissue, and Gene Therapies Advisory Committee. Briefing Document-Oocyte Modification in Assisted Reproduction for the Prevention of Transmission of Mitochondrial Disease or Treatment of Infertility. 2014. www.fda.gov homepage.

107. Ma JY, Li M, Ge Z, Luo Y, Ou XH, Song S, Tian D, Yang J, Zhang B, Ou-Yang YC, Hou Y, Liu Z, Schatten H, Sun QY: Whole transcriptome analysis of the effects of type I diabetes on mouse oocytes. PLoS One 2012, 7(7):e41981.

108. Rugarli El, Langer T: Mitochondrial quality control: a matter of life and death for neurons. EMBO J 2012, 31:1336-1349.

109. Cooper O, Seo H, Andrabi S, Guardia-Laguarta C, Graziotto J, Sundberg M, McLean JR, Carrillo-Reid L, Xie Z, Osborn T, Hargus G, Deleidi M, Lawson T, Bogetofte H, Perez-Torres E, Clark L, Moskowitz C, Mazzulli J, Chen L, Volpicelli-Daley L, Romero N, Jiang H, Uitti RJ, Huang Z, Opala G, Scarffe LA, Dawson VL, Klein C, Feng J, Ross OA, et al: Pharmacological rescue of mitochondrial deficits in iPSC-derived neural cells from patients with familial Parkinson's disease. Sci Trans/ Med 2012, 4:41ra90.

110. Fujikura J, Nakao K, Sone M, Noguchi M, Mori E, Naito M, Taura D, Harada-Shiba M, Kishimoto I, Watanabe A, Asaka I, Hosoda K, Nakao K: Induced pluripotent stem cells generated from diabetic patients with mitochondrial DNA A3243G mutation. Diabetologia 2012, 55:1689-1698.

111. Alirol E, Martinou JC: Mitochondria and cancer: is there a morphological connection? Oncogene 2006, 25:4706-4716.

112. Campello S, Scorrano L: Mitochondrial shape changes: orchestrating cell pathophysiology. EMBO Rep 2010, 11(9):678-684.

113. George SK, Jiao Y, Bishop CE, Lu S: Mitochondrial peptidase IMMP2L mutation causes early onset of age-associated disorders and impairs adult stem cell self-renewal. Aging Cell 2011, 10:584-594.

114. Bukovsky A, Caudle MR: Mammalian neo-oogenesis from ovarian stem cells in vivo and in vitro. In Cell and Molecular Biology and Imaging of Stem Cells. Edited by Heide S. Hoboken: Wiley; 2014. in press.

115. Bukovsky A, Copas P, Virant-Klun I: Potential new strategies for the treatment of ovarian infertility and degenerative diseases with autologous ovarian stem cells. Expert Opin Biol Ther 2006, 6(4):341-365.

116. Bukovsky A: Ovarian stem cells and mammalian neo-oogenesis. Microsc Microanal 2008, 14(Suppl 2):1474-1475. 
117. Bukovsky A, Caudle MR, Virant-Klun I, Gupta SK, Dominguez R, Svetlikova M, Xu F: Immune physiology and oogenesis in fetal and adult humans, ovarian infertility, and totipotency of adult ovarian stem cells. Birth Defects Res C Embryo Today 2009, 87(1):64-89.

118. Bukovsky A: Ovarian stem cell niche and follicular renewal in mammals. Anat Rec (Hoboken) 2011, 294(8):1284-1306.

119. Zhang H, Zheng W, Shen Y, Adhikari D, Ueno H, Liu K: Experimental evidence showing that no mitotically active female germline progenitors exist in postnatal mouse ovaries. Proc Natl Acad Sci U S A 2012, 109(31):12580-12585.

120. Acton BM, Lai I, Shang X, Jurisicova A, Casper RF: Neutral mitochondrial heteroplasmy alters physiological function in mice. Biol Reprod 2007, 77(3):569-576.

121. Zhong Z, Spate L, Ha Y, Li R, Lai L, Katayama M, Sun QY, Prather RS, Schatten $\mathrm{H}$ : Remodeling of centrosomes in intraspecies and interspecies nuclear transfer porcine embryos. Cell Cycle 2007, 6(12):1510-1521.

122. Yabuuchi A, Beyhan Z, Kagawa N, Mori C, Ezoe K, Kato K, Aono F, Takehara $Y$, Kato O: Prevention of mitochondrial disease inheritance by assisted reproductive technologies: Prospects and challenges. Biochim Biophys Acta 1820, 2012:637-642.

123. Johnson J, Canning J, Kaneko T, Pru JK, Tilly JL: Germline stem cells and follicular renewal in the postnatal mammalian ovary. Nature 2004 428(6979):145-150.

124. White YAR, Woods DC, Takai Y, Ishihara O, Seki H, Tilly JL: Oocyte formation by mitotically active germ cells purified from ovaries of reproductive-age women. Nat Med 2012, 18:413-421.

125. Zou K, Yuan Z, Yang Z, Luo H, Sun K, Zhou L, Xiang J, Shi L, Yu Q, Zhang Y, Hou $R, W u$ J: Production of offspring from a germline stem cell line derived from neonatal ovaries. Nat Cell Biol 2009, 11(5):631-636.

126. Bukovsky A, Caudle MR, Svetlikova M, Upadhyaya NB: Origin of germ cells and formation of new primary follicles in adult human ovaries. Reprod Biol Endocrinol 2004, 2:20-50.

127. Bukovsky A, Svetlikova M, Caudle MR: Oogenesis in cultures derived from adult human ovaries. Reprod Biol Endocrinol 2005, 3:17-30.

128. Virant-Klun I, Stimpfel M, Skutella T: Ovarian pluripotent/multipotent stem cells and in vitro oogenesis in mammals. Histol Histopathol 2011 26:1071-1082.

129. Virant-Klun I, Skutella T, Hren M, Gruden K, Cvjeticanin B, Vogler A, Sinkovec J: Isolation of small SSEA-4-positive putative stem cells from the ovarian surface epithelium of adult human ovaries by two different methods. BioMed Res Int/ 2013, 15:1-15. Article ID 690415.

130. Shamsi MB, Govindaraj P, Chawla L, Malhotra N, Singh N, Mittal S, Talwar P, Thangaraj K, Dada R: Mitochondrial DNA variations in ova and blastocyst: implications in assisted reproduction. Mitochondrion 2013, 13:96-105.

131. Bentov YN, Esfandiari N, Burstein E, Casper RF: The use of mitochondrial nutrients to improve the outcome of infertility treatment in older patients. Fertil Steril 2010, 93(1):272-275.

132. Craven L, Tuppen HA, Greggains GD, Harbottle SJ, Murphy JL, Cree LM, Murdoch AP, Chinnery PF, Taylor RW, Lightowlers RN, Herbert M, Turnbull DM: Pronuclear transfer in human embryos to prevent transmission of mitochondrial DNA disease. Nature 2010, 465(7294):82-85.

133. Chiaratti MR, Meirelles FV, Wells D, Poulton J: Therapeutic treatments of mtDNA diseases at the earliest stages of human development. Mitochondrion 2011, 11:820-828.

134. Wang T, Sha H, Ji D, Zhang HL, Chen D, Cao Y, Zhu J: Polar body genome transfer for preventing the transmission of inherited mitochondrial diseases. Cell 2014, 157:1591-1604.

135. Bacman SR, Williams SL, Pinto M, Peralta S, Moraes CT: Specific elimination of mutant mitochondrial genomes in patient-derived cells by mitoTALENs. Nat Med 2013, 9:1111-1113.

doi:10.1186/1477-7827-12-111

Cite this article as: Schatten et al:: The impact of mitochondrial

function/dysfunction on IVF and new treatment possibilities for infertility. Reproductive Biology and Endocrinology 2014 12:111.

\section{Submit your next manuscript to BioMed Central and take full advantage of:}

- Convenient online submission

- Thorough peer review

- No space constraints or color figure charges

- Immediate publication on acceptance

- Inclusion in PubMed, CAS, Scopus and Google Scholar

- Research which is freely available for redistribution 